\title{
Reply to: Comments on the authors' reply to the critical appraisal concerning "Wearable cardioverter defibrillators for the prevention of sudden cardiac arrest: a health technology assessment and patient focus group study"
}

This article was published in the following Dove Medical Press journal: Medical Devices: Evidence and Research

\section{Sabine Ettinger' \\ Michal Stanak' \\ Piotr Szymański \\ Claudia Wild' \\ Romana Tandara Haček ${ }^{3}$ \\ Darija Erčevićs \\ Renata Grenković ${ }^{3}$ \\ Gregor Goetz' \\ Mirjana Huić ${ }^{3}$ \\ 'Ludwig Boltzmann Institute for Health Technology Assessment, Vienna, Austria; ${ }^{2}$ Institute of Cardiology, Warsaw, Poland; ${ }^{3}$ Department for Development, Research, and Health Technology Assessment, Agency for Quality and Accreditation in Health Care and Social Welfare, Zagreb, Croatia}

Correspondence: Sabine Ettinger Ludwig Boltzmann Institute for Health Technology Assessment, 7/20 Garnisongasse, Vienna 1090, Austria $\mathrm{Tel}+43$ । $23681 \mid 9$ ext 25 Fax +43 । 2368119 ext 99 Email sabine.ettinger@hta.lbg.ac.at

\section{Dear editor}

Although we clearly outlined our answers in our previous letter, ${ }^{1}$ we are pleased to clarify further any remaining open issues. There might be diverse views with regard to comparators of the wearable cardioverter defibrillator (WCD). We would like to refer the readers to our previous answer, ${ }^{1}$ where we explained our rationale for choosing the implantable cardioverter defibrillator as one of the comparators. It was selected based on broad indications stated in the CE mark and after discussions with clinicians. Furthermore, in this case, a change of the comparator, ie, the implantable cardioverter defibrillator, would not have led to a different result or conclusion.

As mentioned earlier, observational studies cannot prove efficacy of a particular intervention and randomized controlled trials (RCTs), which aim to reduce bias, are needed. It is important to clarify that according to the EUnetHTA guideline, nonrandomized interventional studies or observational studies might be included only to provide additional information to an RCT on relative efficacy or effectiveness or - under specific conditions when an RCT in not feasible - when very large effects are likely, or for the sake of a temporary decision, ie, early in the life cycle of a new intervention. ${ }^{2}$ The WCD falls under none of these conditions. A recently published RCT by Olgin et $\mathrm{al}^{3}$ on the use of the WCD after myocardial infarction showed that conducting an RCT of the WCD was possible, and more importantly, it showed the need of evidence derived from controlled studies for the sake of establishing efficacy. Citing the authors of the RCT, the WCD "did not result in a significantly lower rate of arrhythmic death than medical therapy during the first 90 days" post myocardial infarction. ${ }^{3}$ This RCT was also included in a recent health-technology assessment (HTA) that concluded that the efficacy of the WCD had not been established. ${ }^{4}$ A similar conclusion was arrived at in another recently published systematic review with a meta-analysis including the RCT as well as retrospective studies of Epstein and Chung (both studies ${ }^{5,6}$ were discussed in the previous letters), suggesting that "more RCTs are needed to justify the continued use of WCD in primary prevention". ${ }^{7}$ Certainly, RCTs are required, since real-world data can potentially be misleading in the evaluation of effectiveness. ${ }^{8}$ 
We do acknowledge that some data from observational studies are available; however, these data cannot be considered of high quality, ie, as data that could have been included for the assessment of effectiveness in our EUnetHTA report, due to the reasons outlined in our previous answer. The EUnetHTA report was undertaken according to the quality standards established by EUnetHTA following relevant guidelines and using the HTA Core Model $^{\circledR}$ for rapid relative effectiveness assessment. ${ }^{9}$ The argument that the inclusion of retrospective studies might mislead the manufacturer to believe that RCTs are not necessary is of course only an additional reason we have excluded this type of study. Nonetheless, one of the responsibilities of EUnetHTA as a European network is to set standards. Retrospective studies comprising larger patient populations were excluded from the assessment of both effectiveness and safety on these outlined grounds of hierarchy of evidence.

We acknowledge your critique with regard to the focus group; however, we disagree with your conclusion. The aim of qualitative research is to explore views, to learn about possible variations in experience and the meaning of this experience, and to create hypotheses that can then be further pursued. ${ }^{10}$ We involved patients in the HTA process in order to give patients a voice and to gather perspectives on areas of their cardiac disease and on the WCD therapy. We did not apply a sampling strategy nor did we aim to reach a point of saturation: the purpose was to collect views from patients, who were selected according to the PICO (population, intervention, comparator, and outcome) question. The patients' input was then fed into the EUnetHTA report. It would be indeed valuable to receive health-related quality-of-life data from an actual WCD study, but these were unfortunately not available. Such data were, however, collected in the RCT by Olgin at $\mathrm{al},{ }^{3}$ but had not yet been published. We have been informed by the authors that these data are currently being analyzed.

There is an agreement among experts that inclusion of patient perspectives can complement HTA processes valuably. ${ }^{11,12}$ Various HTA institutes around the world have systems for patient involvement, and several groups have been formed to further advance and promote patient involvement in HTA. ${ }^{13-15}$ Moreover, the European Commission foresees the involvement of patients in the HTA process in their legislative proposal on strengthening EU cooperation on HTA, which is currently being discussed. ${ }^{16}$

We appreciate again the opportunity to clarify the open issues.

\section{Disclosure}

The authors report no conflicts of interest in this communication.

\section{References}

1. Sperzel J, Staudacher I, Goeing O, et al. Critical appraisal concerning "Wearable cardioverter defibrillators for the prevention of sudden cardiac arrest: a health technology assessment and patient focus group study. Med Devices (Auckl). 2018;11:201-204.

2. European Network for Health Technology Assessment (EUnetHTA). Guideline; Internal validity of non-randomised studies (NRS) on interventions; July 2015. Available from: https://www.eunethta.eu/ wp-content/uploads/2018/01/Internal-validity-of-non-randomisedstudies-NRS-on-interventions_Guideline_Final-Jul-2015.pdf. Accessed December 12, 2018

3. Olgin JE, Pletcher MJ, VittinghoffE, et al. Wearable cardioverter-defibrillator after myocardial infarction. NEngl J Med. 2018;379(13):1205-1215.

4. Chiarolla E, Orso M, Goetz G, Stanak M, Wild C, Jefferson T. Wearable cardioverter-defibrillator (WCD) therapy in primary and secondary prevention of sudden cardiac arrest in patients at risk; Update 2018. AGENAS \& LBI-HTA. Available from: http://eprints.hta.lbg.ac.at/1186/. Accessed January 15, 2019.

5. Epstein AE, Abraham WT, Bianco NR, et al. Wearable cardioverter-defibrillator use in patients perceived to be at high risk early post-myocardial infarction. J Am Coll Cardiol. 2013;62(21):2000-2007.

6. Chung MK, Szymkiewicz SJ, Shao M, et al. Aggregate national experience with the wearable cardioverter-defibrillator: event rates, compliance, and survival. J Am Coll Cardiol. 2010;56(3):194-203.

7. Marsi A, Altibi AM, Erqou S, et al. Wearable Cardioverter-Defibrillator Therapy for the Prevention of Sudden Cardiac Death: A Systematic Review and Meta-Analysis. JACC Clin Electrophysiol. 2019;5(2):152-161.

8. Gerstein HC, McMurray J, Holman RR. Real-world studies no substitute for RCTs in establishing efficacy. Lancet. 2019;393(10168): 210-211.

9. European Network for Health Technology Assessment (EUnetHTA). HTA Core Model $^{\circledR} ; 2016$. Available from: https://www.eunethta.eu/ hta-core-model/. Accessed December 12, 2018.

10. Durand MA, Chantler T. Principles of Social Research. London: Open University Press; 2014.

11. Fried A, Wild C. Beteiligung von BürgerInnen und PatientInnen in HTA Prozessen. Internationale Erfahrungen und Good Practice Beispiele [Participation of Citizens and Patients in HTA Processes. International Experience and Good Practice Examples]. Wien: Ludwig Boltzmann Institut für Health Technology Assessment; 2016.

12. Facey K, Ploug Hansen H, Single A. Patient Involvement in Health Technology Assessment. Singapore: Springer Nature Singapore; 2017.

13. Health Technology Assessment International. Patient and Citizen Involvement. Available from: https://htai.org/interest-groups/pcig/. Accessed December 12, 2018.

14. European Network for Health Technology Assessment (EUnetHTA). Patients; 2018. Available from: https://www.eunethta.eu/stakeholders/ patients/. Accessed December 12, 2018.

15. European Patients' Academy. Closing Report of EUPATI 2012 2017. Available from: https://www.eupati.eu/closing-reporteupati-2012-2017/. Accessed December 12, 2018.

16. European Commission. Health Technology Assessment - Strengthening EU cooperation beyond; 2020. Available from: https://ec.europa.eu/ health/technology_assessment/eu_cooperation_en. Accessed December $12,2018$. 
Dove Medical Press encourages responsible, free and frank academic debate. The content of the Medical Devices: Evidence and Research 'letters to the editor' section does not necessarily represent the views of Dove Medical Press, its officers, agents, employees, related entities or the Medical Devices: Evidence and Research editors. While all reasonable steps have been taken to confirm the content of each letter, Dove Medical Press accepts no liability in respect of the content of any letter, nor is it responsible for the content and accuracy of any letter to the editor.

Medical Devices: Evidence and Research

Publish your work in this journal

Medical Devices: Evidence and Research is an international, peerreviewed, open access journal that focuses on the evidence, technology, research, and expert opinion supporting the use and application of medical devices in the diagnosis, monitoring, treatment and management of clinical conditions and physiological processes. The identification of novel 